\title{
Problems Related to the Use of Conventional and ltem Response Theory Equating Methods in Less Than Optimal Circumstances
}

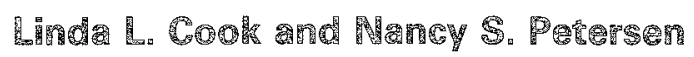

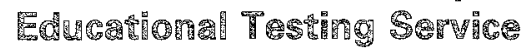

This paper focuses on a discussion of how various equating methods are affected by (1) sampling error, (2) sample characteristics, and (3) characteristics of anchor test items. Studies that examine the effect of analytic techniques for smoothing or modeling marginal and bivariate frequency distributions on the accuracy of equipercentile equating are reviewed. A need for simulation and empirical studies designed to evaluate the effectiveness of analytic smoothing techniques for recovering the underlying distribution when sample size, test length, and distributional shape are varied is identified. Studies that examine the question of whether an equating transformation remains the same regardless of the group unsed to define it are also reviewed. The results of some studies suggested that this may not be a problem for forms of a homogeneous test constructed to be similar in all respects. Results of other studies indicated that examinees who take a test on different administration dates may vary in systematic ways and thus affect equating results. Finally, studies which examine the characteristics of anchor test items are reviewed. It is concluded that whenever groups differ in level and dispersion of ability, special care must be taken to assure that the anchor test is a miniature of the total test.

Many psychometricians view score equating as a subjective art with theoretical foundations because the true relationship between scores on different forms of the same test is never known in practice. Furthermore, actual data never satisfy the

APPLIED PSYCHOLOGICAL MEASUREMENT

Vol. 11, No. 3, September 1987, pp. 225-244

(C) Copyright 1987 Applied Psychological Measurement Inc. $0146-6216 / 87 / 1030225-20 \$ 2.25$ assumptions of the various equating models. Two forms of the same test are never perfectly parallel, equally reliable, or unidimensional. Sample sizes are seldom as large as desired; the ideal data collection design, in which all examinees take both test forms, is not often feasible.

Consequently, when equating scores on two forms of a test, it is necessary to determine how simillar the test forms are with respect to content, difficulty, and reliability. If an anchor test is used, it is also necessary to determine the extent to which the anchor test mirrors the properties of the total tests. It is also important to gather as much information as possible about the extent to which the samples to be used in equating are similar in composition and ability, and are representative of the population for which the test is intended. Further, it is necessary to evaluate the extent to which the data fit the various equating models and how robust the models are to sampling error and lack of model fit, in order to make a sound subjective judgment as to which model is most likely to produce an equating that will be sufficiently accurate for the intended score use.

The purpose of this paper is to discuss some practical problems encountered using conventional and/or item response theory (IRT) methods for score equating. In particular, the discussion will focus on how equating results may be affected by (1) the use of analytic techniques for smoothing empirical distributions, (2) sample characteristics, and (3) properties of the items included in an anchor test. 
It is likely that these problems are too complex to lend themselves to straightforward statistical solutions. However, more research in these areas could lead to practical guidelines for dealing with these issues.

\section{Equinpercentine Equating and Snacothing}

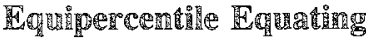

In equipercentile equating, a transformation is chosen such that raw scores on two tests are considered to be equated if they correspond to the same percentile rank in some group of examinees (Angoff, 1971). Equipercentile equating is based on the assumption that the score scales for two tests are comparable with respect to a certain population if the score distributions for the two tests are identical for that population (Braun \& Holland, 1982; Lord, 1950). That is, scores on Form $X$ and Form $Y$ are equated on Population $P$ if the distribution of transformed $Y$ scores is the same as the distribution of untransformed $X$ scores. Equipercentile equating of scores on the two forms of a test can be thought of as a two-stage process (Kolen, 1984): (1) tabulating the relative cumulative frequency distributions for the two forms to be equated; and (2) obtaining equated scores (i.e., scores with the same percentile ranks) on the two forms from these relative cumulative frequency distributions.

In practice, equipercentile equating is not as straightforward as described above. For example, there will seldom be a raw score on Form $X$ with the same percentile rank as a given raw score on Form Y. Thus, to find pairs of scores with the same percentile rank, it is necessary to make the distributions continuous. Consequently, some subjective elements, such as choice of interpolation method, must be introduced into the equating process. Most practitioners use linear interpolation; curvilinear procedures could also be used. However, while choice of interpolation procedure will have some effect on the conversion line, a greater problem with equipercentile equating is probably its susceptibility to sampling error. Equipercentile equating, unlike other equating methods, makes no assumptions about the tests to be equated. The procedure merely compresses and stretches the score units on one test so that its raw score distribution concides with that on the other test. Equipercentile equating is simply an empirical procedure and, as such, is very data dependent. This problem becomes more significant when sample sizes are small.

When sample sizes are small, it is not uncommon to obtain score distributions with zero frequencies for scores within the observed score range and only a few observations, if any, for extreme scores. Conversions based on such data are usually somewhat irregular and step-like. It is unlikely that these irregularities would be closely reproduced if the equating were redone using different samples of the same size; if the equating were redone using very large samples, it is likely that most of the irregularities would disappear and that the conversion would be a more desirable monotonic-increasing function. To mitigate the effects of sampling error on equipercentile equating, practitioners should consider routine use of analytic techniques for smoothing or modeling the frequency distributions and/or the resulting conversion line.

\section{Srmoothining}

A wide variety of analytic techniques for smoothing empirical distributions has been described in the statistical literature. The rolling weighted average of frequencies method described by Angoff (1971) and attributed to Cureton and Tukey (1951), the nonparametric probability density estimation procedures, such as kemal estimators (Tapia \& Thompson, 1978), and the rechniques, such as moving medians, for smoothing empirical distributions (Tukey, 1977) are methods applicable to a wide range of distributional forms requiring minimal statistical assumptions. Regression-based polynomial functions, smoothing cubic spline functions (Reinsch, 1967), and theoretical distributions can be fitted to empirical distributions. Keats and Lord (1962) have suggested use of the negative hypergeometric distribution, and Brandenburg and Forsyth (1974) have suggested use of the Pearson Type I (general beta) function. An IRTbased procedure for estimating the population ob- 
served-score distribution has been described by Lord (1980).

A number of the analytic smoothing procedures described above have been used by practitioners. Few studies, however, have been conducted that were explicitly designed to evaluate the extent to which equipercentile equating can be made more robust to sampling error by use of analytical smoothing techniques. A notable exception is a recent study by Fairbank.

Fairbank (1985) investigated a variety of analytical techniques for smoothing empirical distributions (presmoothers) and conversion lines (postsmoothers) to determine whether statistical smoothing could increase the accuracy of equipercentile equating. Presmoothing techniques used were moving medians, rolling weighted averages, and the negative hypergeometric. Postsmoothing techniques used were the logistic ogive, cubic splines, rolling weighted averages, and linear, quadratic, cubic, and orthogonal regression. For the tests used in the study, the most effective smoothing technique was the negative hypergeometric and the most effective pastsmoother was cubic smoothing splines. It was also found that combining presmoothers and postsmoothers did not result in an improvement beyond that obtained with the more effective of the combined pair (i.e., either the presmoother or the postsmoother) used alone.

The results of the Fairbank study suggest that it may be more beneficial in equipercentile equating to smooth the empirical distributions than to smooth the resulting conversion line. These results possibly are due in part to the fact that the procedures used to smooth the conversion lines were regressionbased. Most definitions of equated scores require that the conversion be symmetric (Angoff, 1971; Lord, 1980). For example, if a score of 45 on Test $X$ is equated to a score of 50 on Test $Y$, then a score of 50 on $Y$ must equate to a score of 45 on $X$. Since the regression of $X$ on $Y$ is generally not the same as the regression of $Y$ on $X$, the use of a regression-based technique for smoothing the conversion line will destroy the symmetry of that conversion.

The smoothing problem becomes more complex when an anchor test data collection design is used.
In an anchor test design, one form of the test is administered to one group of examinees, a second form to a second group of examinees, and a common test to both groups. The groups may be random groups from the same population or they may be non-equivalent or naturally-occurring groups that, consequently, vary in systematic ways. In either case, scores on the anchor test can be used to estimate performance of the combined group of examinees on both the new and old forms of the test, thus simulating by statistical methods the situation in which the same group of examinees takes both forms of the test. Ideally, the anchor test would be composed of questions like those in the two forms to be equated; the higher the correlation between scores on the anchor test and scores on the new or old form, the more useful would be the data.

It may be inappropriate to apply analytic techniques for smoothing empirical distributions to data collected using an anchor test design. Independent application of such techniques to the four marginal distributions prior to equating may destroy the bivariate relationship between each test form and the anchor test, upon which the success of the equating depends. For data collected using an anchor test design, analytic techniques for smoothing the bivariate distributions prior to equating should be more appropriate; however, little work has been done in this area as it relates to equating. A promising set of analytic methods for smoothing twoway contingency tables is based on generalized log. linear models that select the smoothest distribution on the two-way table such that certain key features of the observed data are preserved. For example, a researcher might decide to preserve the correlation, the quadrant totals, and the marginal means, variances, and skewness, or to preserve only the correlation and the marginal means and variances. Models that preserve fewer features of the data are models that perform more smoothing. Additionally, residuals and chi-square tests can be used to help evaluate the quality of the fit between various models.

More research needs to be done on the use of analytic smoothing techniques in the equating process. It is possible that smoothing may significantly increase the robustness of equating results, partic- 
warly when sample sizes are small. Currently, very little is known about the effects of smoothing on equating results. Few studies such as that by Fairbank have been undertaken; it is possible that those results may not be generalizable to other testing situations. Differently shaped distributions may call for different techniques.

\section{Topulation Hnvariance and Sample Selection}

\section{Population Invariance}

There is no universally accepted definition of equated scores. Instead, a variety of definitions have been discussed in the literature (Angoff, 1971; Holland \& Rubin, 1982; Lord, 1977, 1980). However, underlying most of these definitions is the requirement that the equating transformation be population-independent. That is, the equating transformation should be the same regardless of the group from which it is derived.

The question of whether an equating function based on one population also works for another population can be tested with data (Braun \& $\mathrm{Hol}$ land, 1982). One possibility is an investigation of whether the equating transformation between scores on two forms of a mathematics test, derived using random samples from the population taking the test forms, is the same as that derived using samples of all males. The question of population invariance, however, can be compounded by the manner in which the data are collected for the equating experiment. The most commonly used methods of data collection are the anchor test design (described in the preceding section) and the random-groups design, in which the two test forms are administered to random samples from the same population.

Many testing programs offer multiple administrations of their tests, and examinees who select a particular administration date may vary in nonrandom, systematic ways. For example, those raking the rest at one administration may be more able than those taking it at another administration, or those taking the test at one administration may have more relevant coursework than those taking it at another administration. Using a random-groups design, the equating function might be found to be essentially invariant for subgroups taking the test on one administration date, but if the two forms were administered and equated using data from another administration, the two equating functions would differ. In an anchor test design, if the two groups used for the equating take the test on different administration dates, the possibility exists that they may not be subgroups from the same population. If this situation exists, the equating function obtained from such a design may be very problematic. In this section a number of empirical studies designed to evaluate the population invariance properties of equating transformations will be reviewed.

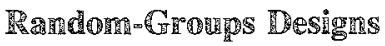

Kingston, Leary, and Wightman (1985) examined the feasibility of using the three-parameter logistic model to perform IRT true-score equating of scores on the Verbal and Quantitative measures of the Graduate Management Admission Test (GMAT; see $\mathbb{L}$ ord, 1980, chap. 13, for a description of IRT equating methods). Population invariance of the equating transformation was of particular interest to these researchers. To investigate this question, Kingston et al. collected data on two forms of the GMAT that were offered at the same administration. Six samples of examinees were selected for each form to provide data for the experimental equatings. Two samples were random, one sample consisted of all males, another of all females, one of "younger" students (ages 21-23), and one of "older" students (29 years of age or older). Each equating was carried out using data from one of the populations (e.g., the two GMAT forms were equated using samples of all males). The results of the study indicated that the equatings were very consistent across the random and subgroup populations for both the Verbal and Quantitative measures. Kingston et al. concluded that differences among converted scores for equatings performed on the six subgroups were negligible.

Angoff and Cowell (1985) examined the population independence of equating transformations derived using conventional linear and equipercen- 
tile procedures applied to forms of the homogeneous Graduate Record Examination (GRE) quantitative test and a specially constituted heterogeneous GRE verbal-plus-quantitative test. Both tests were equated using random samples from the entire population, and using random samples from subgroups defined by sex, race, field of study, and level of performance. Angoff and Cowell evaluated the invariance of the equating transformations by $e x-$ amining departures of the transformations based on the subgroups from the population transformation (i.e., based on the random samples selected from the entire population). Discrepancies between the population and subgroup transformations were evaluated in terms of empirically determined standard errors of equating.

Some discrepancies between subpopulation transformations and the population transformation were noted for both the homogeneous and heterogeneous test. The subpopulation producing the largest discrepancies was a very able Physical Science group. Because the majority of the discrepancies were not significant for the homogeneous test, Angoff and Cowell concluded ". . . that, at least for this homogeneously constructed test - and presumably for other homogeneous tests-the assumption of population-independency is unchallenged" (p. 71).

The Physical Science subgroup presented a more serious problem for the heterogeneous test. Angoff and Cowell hypothesized that discrepancies between the Physical Science subgroup equating transformation and the transformation obtained from the equating based on the total population could possibly be attributed to the fact that the two forms gave unequal weight to questions from the physical sciences and thus were not strictly parallel, and that this lack of parallelism had a greater effect on the equating results obtained for the Physical Science group.

The Kingston et al. (1985) and Angoff and Cowell (1985) studies employed equating samples that were similar in level and dispersion of ability; that is, males and females (or other subgroups used for equating) may have had different ability levels, but the two samples of males that were used for the form-to-form equatings were similar in ability level.
In contrast to the studies reviewed above, the studies reviewed next employed new- and old-form groups who took the test on different administration dates and, consequently, may differ somewhat in ability level and other characteristics that may affect test scores.

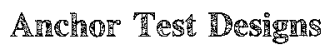

Cook, Eignor, and Taft (1985) examined the results of equating two forms of a secondary school biology achievement test, which had been constructed to be reasonably parallel to each other. Their study employed one old-form sample and two different new-form samples. The old-form sample was randomly selected from a Fall administration of the test. One new-form sample was randomly selected from a Spring administration of the test and the second sample was randomly selected from a Fall administration. It should be noted that students taking the biology test in the spring are typically able students who have recently completed a course in biology. Students raking the test in the fall are less-able students, the majority of whom have not formally studied biology for 6 to 18 months. It seems logical to suspect that some degree of forgetting could affect what the test is actually measuring for the Spring and Fall populations (e.g., immediate recall may be more important for some content classifications than for others), and thus could affect total test scores as well as performance on the anchor test items.

Table 1 contains summary statistics which describe the performance of the three samples on the two forms of the total test and the common anchor test ( 58 common items included as part of the total score on both the new and old forms of the test). It can be seen, from the data presented in Table 1 , that the two new-and old-form Fall samples are very similar in their performance on the 58-item anchor test. On the other hand, the new-form Spring sample performed very differently on the anchor test items.

Differences between performance on the 58 common items for the Spring and Fall samples are best illustrated by an examination of the plots shown in Figure 1. These plots show the relationship be- 
Table 1

Raw Score Sumary Statistics for Biology Tests and Common Item Sets

\begin{tabular}{|c|c|c|c|c|c|}
\hline $\begin{array}{l}\text { Form } \\
\text { and } \\
\text { Test }\end{array}$ & n & M & Mean & $\begin{array}{l}\text { Standerd } \\
\text { Deviation }\end{array}$ & $\begin{array}{l}\text { Correlation of } \\
\text { Equating Test } \\
\text { With Total Test }\end{array}$ \\
\hline \multicolumn{6}{|c|}{ old Forme (Fall Sample) } \\
\hline Old Form & 99 & 2408 & 46.33 & 18.26 & \\
\hline Anchor Test & 58 & & 25.62 & 11.42 & .96 \\
\hline \multicolumn{6}{|c|}{ New Form (Spring Sample) } \\
\hline Old Form & 95 & 3892 & 53.71 & 17.61 & \\
\hline Anchor Test & 58 & & 32.89 & 11.42 & .97 \\
\hline \multicolumn{6}{|c|}{ New Form (Fall Sample) } \\
\hline New Form & 95 & 3653 & 44.74 & 17.56 & \\
\hline Anchor Test & 58 & & 25.65 & 11.27 & .96 \\
\hline
\end{tabular}

*Raw score summary statistics for the two new-fordi samples may be directly compared. However, due to differences in test difficulty and test length, comparisons should not be made of these statistics with those obtained for the old form of the test.

tween equated delta values (transformed item difficulty values; Henrysson, 1971) for the Fall oldform groups and the Spring and Fall new-form groups.

It is obvious, from examination of the plots shown in Figure 1, that the item difficulty indices (deltas) demonstrate more scatter for the Spring new-form/ Fall old-form combination than they do for the Fall new-form/Fall old-form pairing. A numerical index of the disagreement between these indices for the Spring/Fall combination, and of their close agreement for the Fall/Fall combination, is shown by the correlation coefficients given below the plots. These data strongly indicate that the 58 common items contained in the new and old biology test forms measure the same underlying constructs for the two Fall samples, but are differentially difficult for the Spring and Fall groups. Thus, it is quite likely that the two biology test forms, even though constructed to be very parallel, measure different skills or constructs depending upon whether they are administered to a Spring or Fall group.

The two biology test forms were equated to each other using Tucker, Levine, and equipercentile equating methods (see Angoff, 1982, designs 5.1, 5.4 , and 5.3, respectively, for a description of these methods). IRT true-score equating based on the threeparameter logistic model (Lord, 1980, p. 193) was also performed. All equatings were implemented using (1) the Spring new-form/Fall old-form combination and (2) the Fall new-form/Fall old-form pairing. The results of these equatings (and those of other equatings to be discussed later) are presented in Table 2. Perusal of the data shown in Table 2 indicates that all of the equatings using the Spring new-form/Fall old-form combination resulted in scaled-score means at least 15 points higher than those based on the Fall new-form/Fall oldform combinations.

Several questions may be asked about these results. Are the equatings discrepant due to the differences in ability level of the new- and old-form samples, or are they discrepant because the test is measuring different (non-parallel) constructs for the Spring and Fall groups? Another closely related question is: Will an equating transformation determined by using samples from one of these groups remain invariant for the other group? This latter question was investigated by Cook (1984). In her study, two different forms of the biology test were equated using new-and old-form samples from Fall administrations, and the equating was then repeated 


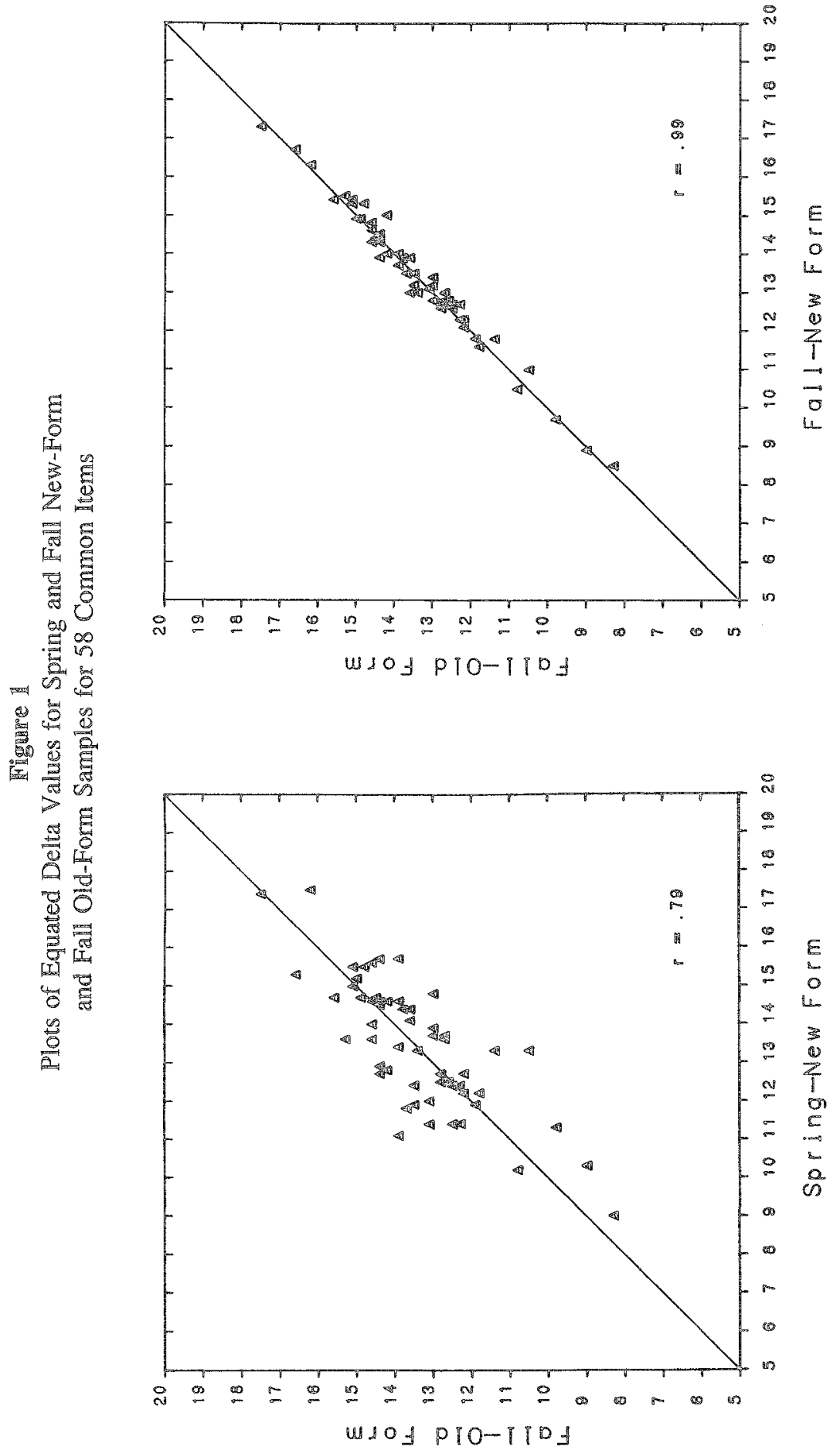

Downloaded from the Digital Conservancy at the University of Minnesota, http://purl.umn.edu/93227. May be reproduced with no cost by students and faculty for academic use. Non-academic reproduction requires payment of royalties through the Copyright Clearance Center, http://www.copyright.com/ 
Table 2

Scaled Score Summary Statistics Resulting From Combinations of Equating Method, Common Iten Set, and Fquating Sample*

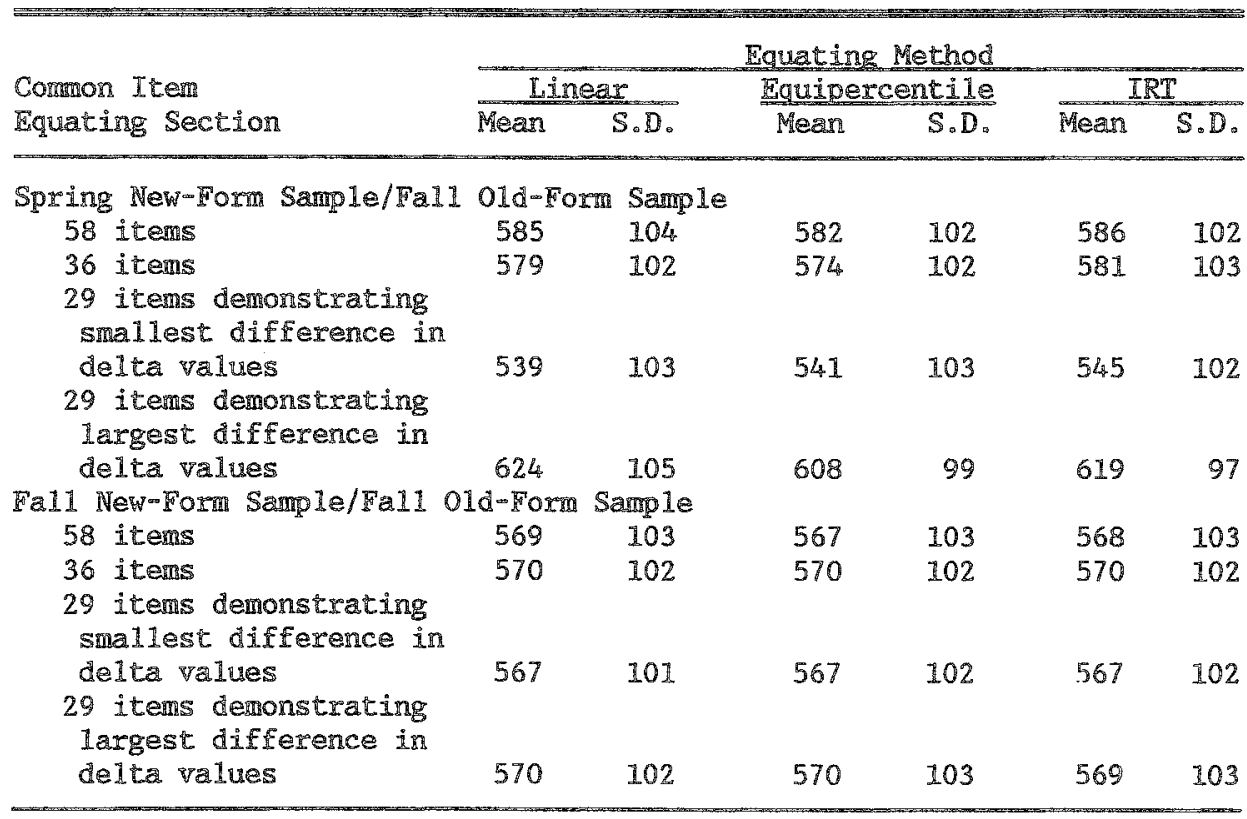

"RaW score frequency distributions used to compute scaled score surnarary statistics were obtained from Spring total group ( $N=23,405)$.

using new- and old-form samples from Spring administrations. Although the Spring and Fall groups differed in level and dispersion of ability, the two Spring samples used for the equatings were similar to each other, as were the two Fall samples. The situation is similar to that investigated by Angoff and Cowell (1985) and Kingston et al. (1985).

The results of these equatings are compared in Table 3. Examination of these data reveals that the equating transformation determined using the Spring/ Spring combination results in reported scores that are 10 points higher, throughout most of the score range, than those obtained by a transformation determined using Fall/Fall samples. These results suggest that the Spring and Fall groups taking the biology test may not be subgroups from the same population, and that the biology test may not be measuring the same thing for these two populations.

A final question that comes to mind when reviewing the data presented in Table 2 (for the equat- ings based on 58 common items) is: Why are the IRT true-score results as affected by differences in group ability as are the results based on the observed score equating methods? Lord and Wingersky (1984) pointed out that if the IRT model holds, true scores will be equated for all subpopulations of examinees. The fact that the results based on the Spring new-form/Fall old-form and Fall newform/Fall old-form groups differ so much seems to indicate that the assumptions of the IRT model are not met or, as previously hypothesized, the Spring and Fall groups are not subgroups of the same population.

\section{SีH}

Kingston et al. (1985) and Angoff and Cowell (1985) found little difference among equating transformations obtained from subgroups of a specific population when the tests to be equated were 
Table 3

Biology Test Raw-to-Scale Linear Conversions

Resulting From Fall and Spring

New-Form/01d-Fom Combination

\begin{tabular}{ccc}
\hline $\begin{array}{l}\text { New Form } \\
\text { Raw Score }\end{array}$ & $\begin{array}{c}\text { Fa11 New-Form/ } \\
\text { Fall old-Form }\end{array}$ & $\begin{array}{c}\text { Spring New-Form/ } \\
\text { Spring O1d-Form }\end{array}$ \\
\hline 100 & 790 & 800 \\
90 & 740 & 750 \\
80 & 680 & 690 \\
70 & 630 & 640 \\
60 & 570 & 580 \\
50 & 520 & 530 \\
40 & 470 & 470 \\
30 & 410 & 420 \\
20 & 360 & 370 \\
10 & 310 & 310 \\
0 & 250 & 260 \\
\hline
\end{tabular}

constructed to be parallel and homogeneous in content and the equating samples were similar in ability. Angoff and Cowell found that when heterogeneous tests were equated under the same conditions, the results were not stable across all subgroups.

The results of the semdies conducted by Cook et al. (1985) and Cook (1984) may be contrasted to those obtained by Kingston et al. and Angoff and Cowell. Cook et al. found that when relatively parallel forms of an achievement test were equated using groups of students who took the tests on different administration dates, both conventional and IRT equating results were seriously affected. They concluded that the disparate equating results were obtained because students taking the test at the different administrations differed in relative recency of their coursework. This difference in recency of training interacted with test content. Thus the test measured different constructs, depending on the sample of examinees to whom the test was adninistered.

\section{Properties of Anechor Test Items}

\section{A}

In the previous section of this paper, empirical studies that investigated the invariance of equating transformations were reviewed. The studies focused on how equating results may be affected by examinee characteristics. Some of the studies involved the use of an anchor test data collection design. When using an anchor test design, at researcher must also be concerned with the properties and characteristics of the anchor test items in relation to the total test. As mentioned above, an anchor test is used to reduce equating error resulting from differences in ability between new and old form groups. The anchor rest may consist of common items that are scattered throughout the new and old form (internal anchor test); or the anchor test may appear in a separately-timed section of the test (external anchor test).

In the context of IRT equating, anchor tests are usually referred to as linking tests or linking items. The linking items are used to "scale" item paraneter estimates. If, prior to equating, new and old test forms are given to groups that differ in level of ability, the $\mathbb{R T T}$ parameter estimates for the two forms will be on different scales. It is well known that IRT equating requires that the item parameter estimates for two test forms be on the same scale prior to equating, and that the quality of the equating depends upon how well the item scaling is accomplished.

This section reviews empirical and simulation studies that focus on how the properties of anchor 
tests affect conventional and $I R T$ equating results. With regard to conventional equating methods, the properties of the anchor test that will be discussed are length, parallelism with the tests to be equated, and consistency of item difficulty for new and old form groups. With regard to IRT equating, anchor test properties such as length, difficulty, and size of the standard errors of estimation of the items will be discussed; also discussed will be studies that compare methods for placing item parameter estimates on the same scale (concurrent calibration vs. an item transformation method).

\section{Converational Methods}

Klein and Kolen (1985) investigated the relationship between anchor test length and accuracy of results obtained using conventional equating methods. The test used was a certification test which contained 250 multiple-choice items. These researchers, using data from a Fall administration of the test, separated examinees into similar and dissimilar ability level groups. Within each group, they equated the test to itself several times using the Tucker method and anchor tests of 20,40,60, 80 , and 100 items. The results of their study indicated that when groups are similar in ability, anchor test length has little effect on the quality of equating. However, when the groups used for equating differ in level of ability, length of the anchor test becomes very important.

Klein and Kolen concluded that "when the tests being equated were very similar, or in this particular case, identical, and the groups of examinees very similar, substantially more accurate equating was not obtained by lengthening the anchor. However, longer anchors did result in more accurate equating when the groups of examinees were dissimilar" (p. 10). They emphasized that the results of this study are based on anchor tests that correspond very closely to the total test with respect to content representation, difficulty, and discrimination.

Resulis of the Cook et al. (1985) study are also pertinent to a discussion of anchor test length. Figures 1 through 4 contain plots of the 58 common items used in the equatings previously discussed,
36 common irems chosen by content experts to represent concepts in biology most likely to remain stable across the Spring and Fall groups, 29 common items for which delta values (item difficulty indices) changed the least for the Spring and Fall groups, and 29 common items for which delta values changed the most for the two groups. The plots shown in Figures 1 through 4 compare delta values obtained for the different item sets given to the very able Spring new-form group and the less able Fall old-form group with those obtained for the Fall new-form and Fall old-form groups that are similar in level of ability. It is fairly clear, from the data presented in Figures 1 through 4 , that for all subsets of items (different anchor tests), the items are differentially difficult for the Spring and Fall groups and similar in level of difficulty for the two Fall groups. The question is: What effect does this have on the equating results?

Table 2 presents summary statistics for the Spring total group based on the results for the equatings, employing the various sets of anchor test items, for the Spring/Fall and Fall/Fall sampling combinations. Notice that when the groups differ in level of ability (Spring/Fall samples), the different anchor tests yield very disparate equating results. However, when the groups are similar in level of ability (Fall/Fall samples), the various anchor tests yield equating results that are in close agreement. These findings, in conjunction with those obtained by Klein and Kolen, strongly indicate that when groups differ in level of ability (as they typically do for anchor test designs), special care must be taken when selecting the set of common items constituting the anchor test.

Klein and Jarjoura (1985) investigated, for conventional equating methods, the importance of the content representation of the anchor test. For their study, they equated a 250-item multiple-choice test to itself through three intervening links or anchor tests. The success of the equating was judged by how closely the identity relationship of equating a test to itself was recovered. For the representative chain of equatings, they used three 60 -item anchor tests, all representative of the content of the total tests. For the nonrepresentative chain, the first anchor consisted of 101 items, the second of 105 


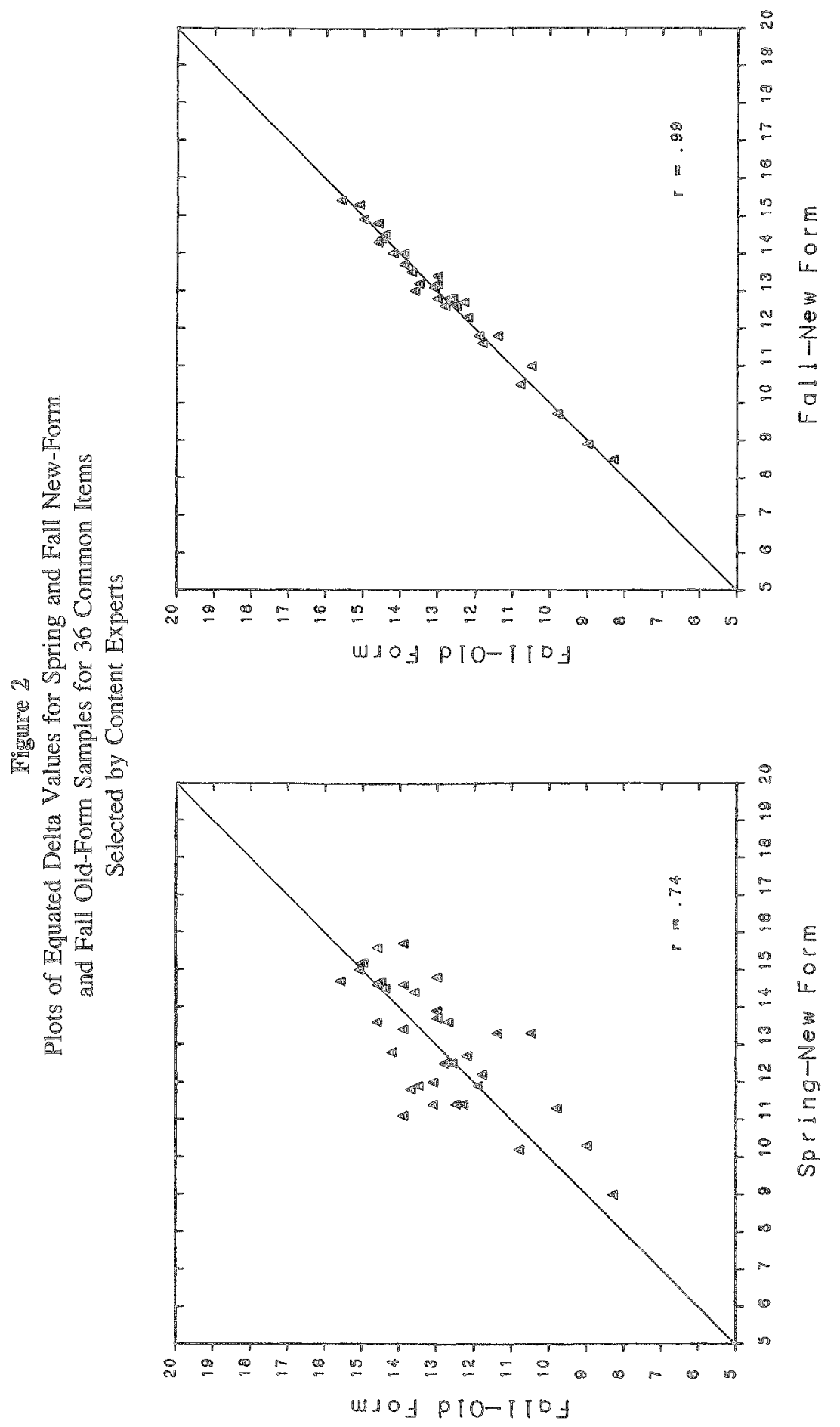

Downloaded from the Digital Conservancy at the University of Minnesota, http://purl.umn.edu/93227. May be reproduced with no cost by students and faculty for academic use. Non-academic reproduction requires payment of royalties through the Copyright Clearance Center, http://www.copyright.com/ 


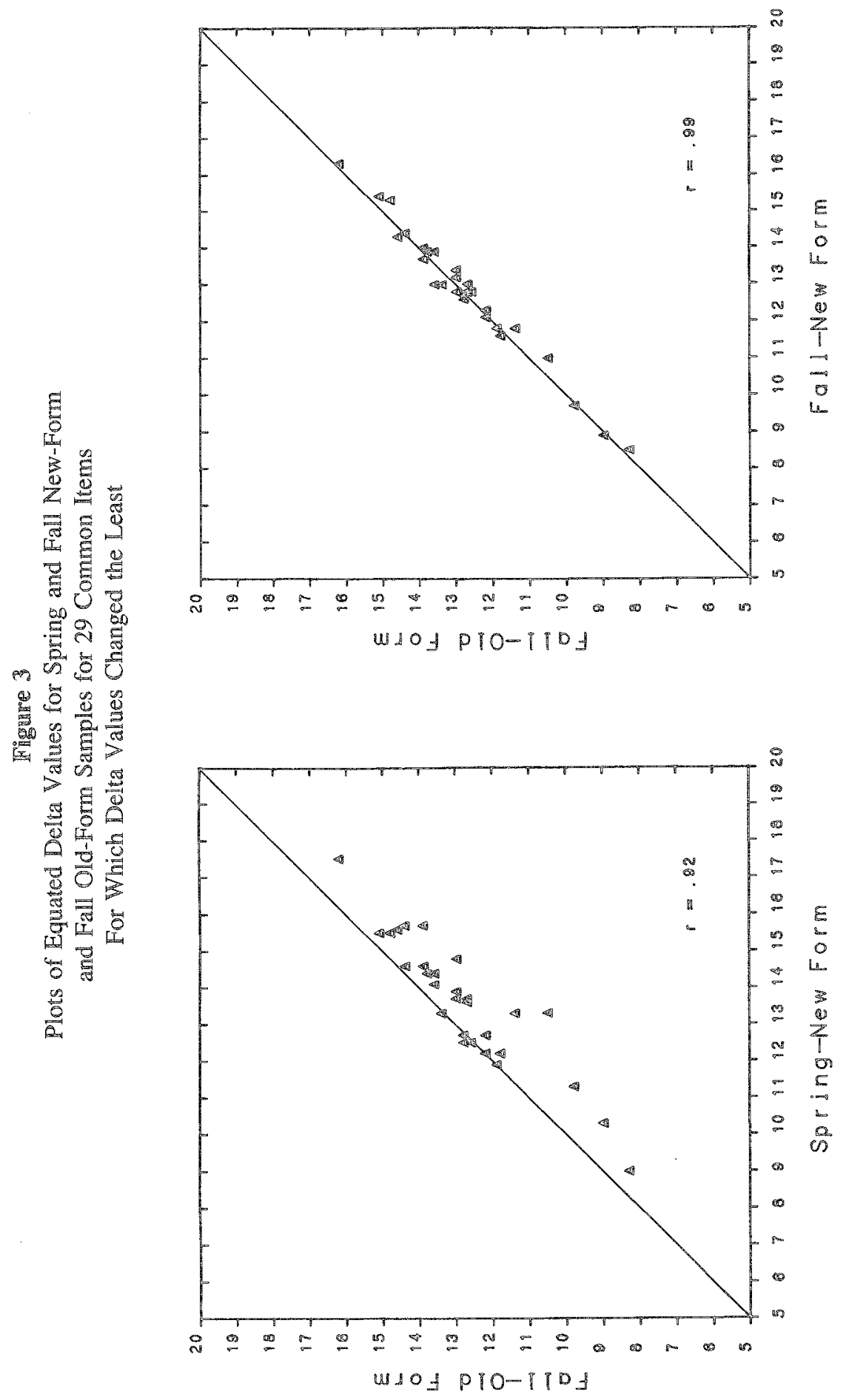

Downloaded from the Digital Conservancy at the University of Minnesota, http://purl.umn.edu/93227. May be reproduced with no cost by students and faculty for academic use. Non-academic reproduction requires payment of royalties through the Copyright Clearance Center, http://www.copyright.com/ 


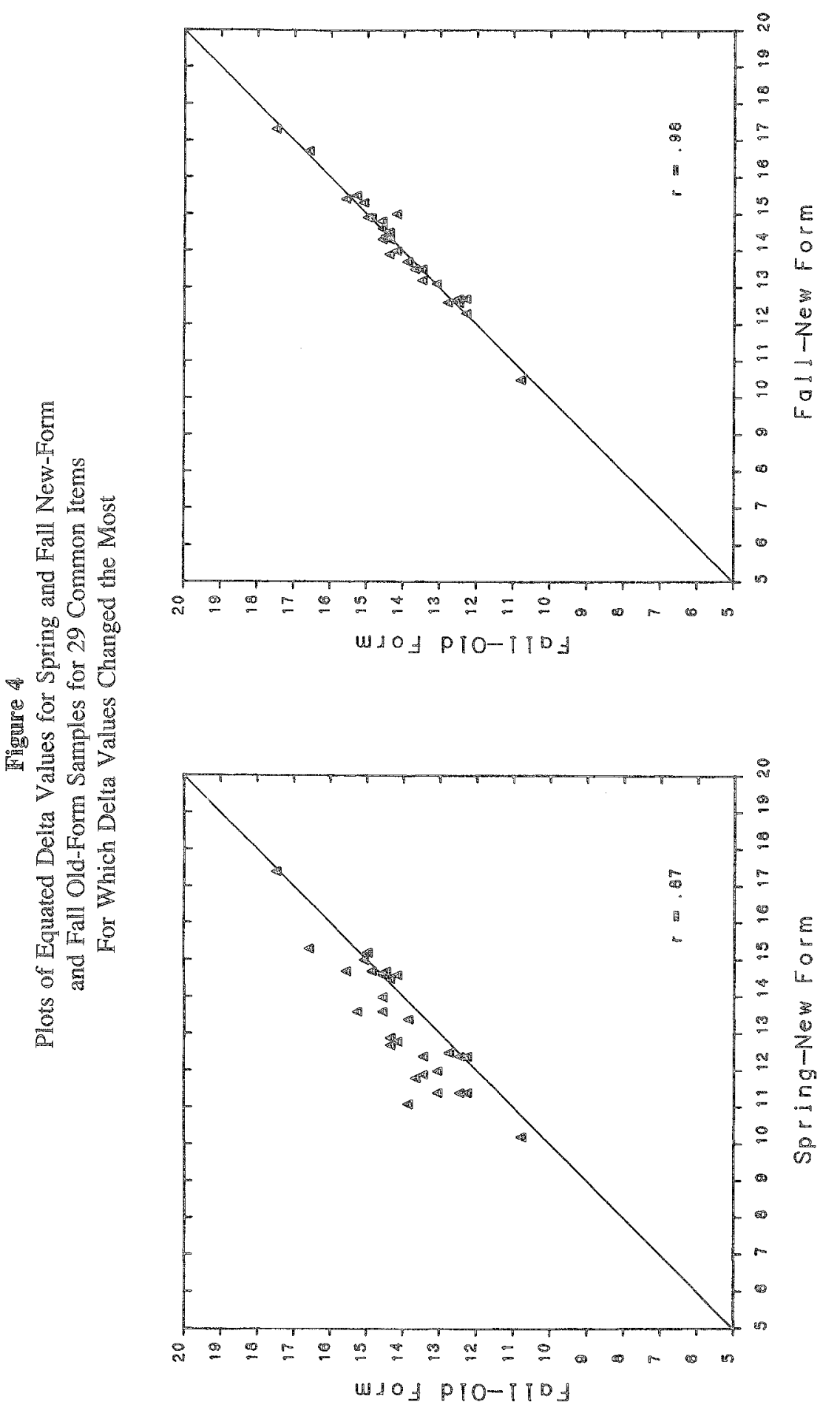

Downloaded from the Digital Conservancy at the University of Minnesota, http://purl.umn.edu/93227. requires payment of royalties through the Copyright Clearance Center, http://www.copyright.com/ 
items, and the third of 60 items. Only the 60-irem anchor was representative of the rotal test content; all anchors were similar to the total test in average difficulty. Both Tucker observed-score and Levine true-score equating methods were used.

Based on the results of their study, $\mathbb{K}$ lein and Jarjoura concluded that it was quite important to use content-representative anchors. They explained this in the following way: "Consider an extreme example in which two test date groups differed on only some of the content areas. If a nonrepresentative anchor consisted of items from only the content areas on which there were no differences, it would fail to reflect the true differences between the groups on the full test form" (p. 203).

The results of the three studies reviewed indicate that the properties of an anchor test can seriously affect conventional equating results. Both the number of items included in an anchor test and the content representativeness of the items appear to be important variables. However, these variables seem to decrease in importance as the equating samples become more similar in level and dispersion of ability. Because anchor test designs are usually used in situations where groups differ in ability level, the results of these studies have serious implications for this type of design.

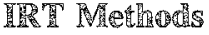

IRT equating applications use a variety of procedures for placing parameter estimates from separate item calibrations on the same scale. Cook and Eignor (1981) and Stocking and Lord (1983) have provided detailed descriptions of many of the commonly-used transformation methods. For score equating applications, users of the three-parameter logistic model and the LOGIST computer program (Wingersky, 1983) make use of a set of linking (common) items on each test to place parameter estimates for items appearing on two or more test forms on the same scale. This "scaling" can be essentially accomplished in two ways. One way, referred to as concurrent calibration (Petersen, Cook, \& Stocking, 1983), involves the estimation of item parameters for the test forms and the linking items in a single calibration run. This procedure auto- matically places parameters for all items on the same scalle. The second procedure involves estimation of item parameters for one or more test forms along with a set of linking items in one calibration run, and the estimation of item parameters for one or more different forms and the linking items in another calibration rum. The item parameter estimates for the various test forms are then placed on the same scale using a linear transformation based on the relationship between the parameters for the linking items obtained in the two calibration runs (see Stocking \& Lord, 1983).

Once item parameter estimates for the various forms have been placed on the same scale, it is possible to equate scores on the test forms using IRT true-score equating procedures (Lord, 1980). Most of the research conducted to date has esserntially addressed the question of how many common irems are necessary to place item parameter estimates on the same scale prior to IRT irue-score equating.

Vale, Maurelli, Gialluca, Weiss, and Ree (1981) investigated the problem using simulated data with 5,15 , and 25 common items and three different shapes of the linking test information curve: peaked, normal, and rectangular. Vale ef al. assumed that good estimates for the linking items were already known, and they required that there be enough linking and unique isems to obtain good ability estimates. For each examinee, two estimates of ability were obtained, one from the linking items and the other from the unique items. The estimates were used to determine the transfonnation required to put the unique items onto the common scale. For this method of placing parameter estimates on a common scale, Vale et al. found that 15 to 25 items were necessary. They also found that linking nests with a rectangular or normal information funcfion gave befter results than those with a peaked information function.

McKinley and Reckase (1981) studied the number of common items problem in the context of the construction of large item pools. They worked with real data from a multidimensional achievement rest covering a number of different areas of achievement. MicKinley and Reckase concluded that 5 items were not adequate, 25 items were better than 15 , 
but 15 items were adequate for linking with a conchrrent calibration design.

Raju, Edwards, and Osberg (1983) studied linking test size in the context of vertical equating; they also used real data. Unilike the previously described studies, Raju et al. made use of the Rasch model along with the three-parameter logistic model. Parameter estimates were derived in separate calibra1ion runs; linking constants were determined by setring equal the standard deviates of item difficulty estimates obtained for the linking itens in the separate calibrations. Raju et al. found, for both models, that short linking tests - with as few as six or eight items-performed almost as well as longer linking tests containing two or three thmes as many items. They also found that the three-parameter model provided more acceptable equating results.

Wingersky and $\mathbb{L}$ ord (1984) studied the problem of the number of linking irems in the context of concurent calibration. In the most extreme case studied, Wingersky and Lord found that two good linking items (items whth small standard errors) worked almost as well as a set of 25 linking items.

Wingersky, Cook, and Eignor (1986) investigated the effects on tRT true-score equating results of the characteristics of the linking items. The stedy was carried out using the three-parameter logistic IRT model and monte carlo procedures. The true item parameters were taken from the estimated parameters obtained from LoGIST calibrations of item responses from selected administrations of the verbal sections of the College Board Scholastic Aptivude Test (SAT-V) so that the simulated data reflected actual test data. The characteristics of the items were investigated for wo of the common linking or scaling designs: concurrent calibration and the characteristic clirve transformation method (see Stocking \& Lord, 1983). The effects on IRT true-scorc equating results were studied for the two scaling designs using three different linking test lengths (10,20, and 40 items), two variations in the size of the stardirid errors of estimation (SEE) of the linking items, and two distributions of examinee ability (peaked and uniform).

The results of the Wingersky et al. study showed very litule difference in equating results based on placing item parameter estimates on the same scale using a concument calibration procedure or a characteristic curve method of scaling. As expected, the authors found, for both scaling methods, that the accuracy of the equating results improved as the number of linking items was increased. The characteristic curve transformation method seemed to require slightly more items than the concurrent calibration procedure. A surprising finding was that, for both scaling procedures, linking items chosen to have SEEs similar to those typically found for SAT-V linking items provided slightly better equating results than those deliberately chosen to have small SEES. They also found that the equating result were slightly better when a uniform distribution of abilities, rather than a peaked distribution of abilities, was used to estimate paramerers for the linking items.

Kingston and Dorans (1984) examined what they referred to as "context effects" on IRT true-score equating. They defined context effects as occurring when examinees respond differently to an item depending upon its location within a test. Kingston and Dorans investigated the susceptibility to item location effects of 10 item types from the Graduate Record Examination (GRE) General Test. To study location effects, they administered two versions of Form $B$ of the GRE to random samples from the same population. One version contained items in the typical operational locarion; the second version contained the same items in non-operational locauions. In genera1, Kingston and Dorans found some practice and fatigue effects for most of the item types studied.

To evaluate the effect of item location on IRT true-score equating, Kingston and Dorans equated the two versions of Form $B$ to Form $A$ (a form of the GRE General Test that had been previously placed on scale) and compared the results. They found that the two equatings of the Verbal measure of the test were in close agreement. In contrast, the equating of the Quantitative measure that resulted from the ase of items in the non-operational position showed a small but consistent bias, which they atributed mostly to practice effects on the data interpretation items. The equating results that were the most profoundly affected were those for the Analyical measure. The analytical item types 
showed extreme sensitivity to item location, which was reflected in a difference in means of almost 30 converted score points between the equatings of Form $B$ with items in the operational and nonoperational positions.

Kingston and Dorans concluded that susceptibility to location effects depends upon the lisem type. Review of the analytical item types showed the items to be quite complex with extensive and complicated directions. They hypothesized that once the directions were understood, the iterns were fairly easy to handle. Hence, the difficulty of an individual item depends in part upon how many items of the same type precede it.

The results of the Kingston and Dorans study have important implications for equating applications such as IRT-based preequating. IRT preequating is a variant of IRT true-score equating that uses a data collection design involving the calibration of items (typically using pretest data) and subsequent equating of test forms prior to a test's administration. Because items will usually not appear in the same position in a final form of the test as when they are precalibrated, the appropriateness of an equating transformation derived from preequating requires that the parameter estimates of the items not be influenced by location effects.

Eignor (1985) examined the possibility of preequating the Verbal and Mathematical sections of the Scholastic Aptitude Test (SAT) using pretest items administered in a variable section which is given along with the operational sections of the SAT. For his study, Eignor calibrated the Verbal and Mathematical sections of two SAT forms using pretest data, and then preequated these forms to existing SAT forms. The results of the preequating were compared to those obtained when the test forms were operationally equated using IRT truescore equating. Eignor concluded that the results of the preequating of the Verbal section for one form were quite successful, while those obtained for the second form exhibited discrepancies of up to 20 scaled-score points between the preequating results and the operational results.

The preequating of the mathematical sections of both forms studied provided results at least as discrepant as those for the most problematic verbal section, and thas were a source of concern. Eignor hypothesized that discrepancies between difficulty parameter estimates obtained when items were calibrated in multiple pretest sections and then as part of an intact final-form (resulting in differences between preequating and operational equating transformations) could possibly be attributed to the type of location effects described by Kingston and Dorans (1984). However, Eignor's design did not allow him to test this hypothesis.

Eignor also suspected that discrepancies in the pretest and intact final form item difficulty parameter estimates, and the resultant IRT equatings, may have been the result of differences in the ability levels of the multiple groups used for calibration. Recall that Kingston and Dorans carried out their study using random groups of examinees from the same administration; thus, differences in group ability would not be a factor in the results they observed. It seems clear that if it is possible to obtain results such as those described by Kingston and Dorans for the Analytical measure of the GRE when groups are similar in level of ability, then a preequating design such as Eignor's, where item parameter estimates (and ultimately the equating based on these estimates) are subject to both location effects and differences in group ability, can be considered very problematic.

The $\mathbb{R T}$ studies reviewed reached varying conclusions as to the effect of anchor test length on equating results. The Vale et al. (1981) and Raju et al. (1983) studies examined linking test size in the context of separate calibration runs. Valle et al. suggested that at least 15 items may be necessary, while Raju et al. found adequate linking with as few as 6 common items. The McKinley and Reckase (1981) and Wingersky and Lord (1984) studies explored linking test size in the context of concurrent calibration. McKinley and Reckase suggested that 15 items are needed for adequate linking, while Wingersky and Lord suggested that as few as 5 items may be needed. The Wingersky et al. (1986) study indicates that improved results are obtained for both a concurrent calibration procedure and a characteristic curve transformation method for longer linking tests. Furthermore, little difference was found between equatings based on item 
parameter scalings performed using the concurrent calibration procedure and the characteristic curve method. In addition, their results indicate that slightly more accurate equatings are obtained if a uniform rather than a peaked distribution of ability is used to estimate parameters for the linking test items.

\section{Sำ}

The conventional equating studies reviewed clearly indicate that the properties of an anchor test are of greater concern as the samples used to equate tests diverge more in level of ability. The results of the Cook et al. (1985) study dramatically illustrate how equating results can be very disparate for different sets of common items if the groups used for equating differ in level of ability. On the other hand, these same common item sets yield results that exhibit a high level of agreement when the groups are similar in ability level. The results of the study by Klein and Kolen (1985) are similar to those obtained by Cook et al.; that is, anchor test length only became a serious factor when the groups differed in level of ability. The results of the study by Klein and Jarjoura (1985) indicate that content parallelism of the anchor test to the total test is an important factor when the two groups used for the equating differ in level of ability. Although differences in group ability were not specifically addressed in any of the IRT studies reviewed, it is likelly, as with the results obtained for the conventional studies, that the properties of linking items used for IRT item parameter scaling interact with such differences, should they exist.

The Kingston and Dorans (1984) and Eignor (1985) studies that evaluated the effects of the properties of linking items on IRT true-score equating clearly indicate that item position is a key factor. However, because it is usually possible for most equating designs to maintain the position of linking items at least reasonably well, this factor only becomes a major concern for IRT preequating designs. Although the present authors canmot cite a formal study, it is an established practice when using conventional equating to maintain the position of anchor test items across new and old test forms that are to be equated. If IRT true-score equat- ing is affected by item location to such an extent, conventional equating results may well be similarly affected.

\section{Conclussions}

This paper has discussed ways in which various equating methods are affected by (1) sampling error, (2) sample characteristics, and (3) characteristics of anchor test items. Unfortunately, the authors are unable to offer, as an outcome of this discussion, a universal procedure for obtaining accurate equating results. However, it is possible to make some practical suggestions for practitioners to follow when equating, and to outline future research directions.

Paucity of data for equating is a common problem for testing programs that of fer tests for certification or licensure purposes or that offer tests that measure competence in a particular subject area. The small sample problem is exacerbated when the tests are long. Some research has been done that suggests that the accuracy of equipercentile equating may be improved through the use of analytic techniques for smoothing or modeling marginall and bivariate frequency distributions. More formal research in this area is needed. There is a need for simulation and empirical studies designed to evaluate the effectiveness of analytic smoothing techniques for recovering the underlying distribution when sample size, test length, and distributional shape are varied. Such research could lead to guidelimes for the practitioner, and thus could help to eliminate some of the "subjectiveness" in operational equipercentile equating decisions.

Definitions of equated scores require that the equating transformation be the same regardless of the group from which it is derived. Some of the studies reviewed suggest that this may not be too serious a problem for forms of a homogeneous test that are constructed to be as similar as possible in all respects. However, most testing programs offer their tests on multiple dates throughout the year, and most of the studies reviewed have not examined whether their results would hold if the same test forms were reequated using samples from a different administration date. Examinees who take 
a test on different administration dates are selfselected, and thus may vary in systematic ways (e.g., recency of relevant coursework) which may be related to test performance. This is probably a greater problem for achievement-type tests than for aptitude-type tests. As the Cook et al. (1985) study indicated, an achievement test may measure different skills and abilities for groups taking the test on different administration dates.

More testing programs need to evaluate the extent to which their operational equating results are population-invariant. They need to examine the similarity in equating results for major population subgroups taking test forms at different administration dates. If the resulting equating transformations are not the same, it may be necessary to take this into account when selecting samples and administration dates for conducting equating. It may also be necessary to explicitly describe, to test score users and recipients, the characteristics of the group for which scores can be considered to have the same meaning.

The effectiveness of an anchor test depends on how closely the anchor test mirrors, in content and statistical properties, the characteristics of the tests that are to be equated. The studies reviewed indicate that the extent to which conventional equating results are altered by departures from this ideal situation depends, to a large degree, on differences between the level and dispersion of ability of the equating samples. It is apparent that when groups vary in ability (the typical anchor test sicuation), special care must be taken to ensure that the anchor test is a miniature of the tests to be equated. It is also apparent, from the results of Cook et al. (1985) and other studies, that anchor test items should be examined to determine if they are differentially difficult for the new and old form groups.

The studies that examined the effect of the characteristics of the linking items on IRT true-score equating focused on several different properties of the items. The most compelling results were those found in the Kingston and Dorans (1984) and Eignor (1985) studies. The results of these studies indicate that the scaling of the parameter estimates depends, to some extent, on the relative position of the linking items in the new and old forms of the test.

Results of the IRT equating studies that examined the effect of the number of linking items, the size of the standard errors of estimation of the item parameters, and the type of scaling procedure did not provide clear guidelines. It is important to note that none of these studies systematically investigated (as was done in the conventional anchor test studies) the effect on item parameter scalling of (1) lack of content representativeness of the linking items to the total test, or (2) the difference in ability levels of the new- and old-form groups.

An investigation of how both of these factors affect item parameter scaling and their interaction with the number of linking items, the position of the linking items, and the scaling procedure used would certainly be worthwhile. In the absence of such a study or studies, it would appear that, when equating tests that are administered to groups that differ in level of ability, regardless of whether IRT true-score or conventional equating procedures are being used, common items should be selected that are a miniature of the tests to be equated and these items should remain in the same relative position when administered to the new- and old-form groups. It would also seem prudent to evaluate the differential difficulty of the common items administered to the equating samples, particularly when equating samples come from different administration dates.

The practical issues addressed in this paper are among those that are frequently encountered in equating applications. These issues have been addressed using available research and the authors' own personal experience. In so doing, a number of additional IRT and conventional equating issues in meed of clarification have become apparent. The authors are optimistic that as more equating research is done and as more psychometricians gain practical equating experience, many of the issues will be resolved.

\section{留efereres}

Angoff, W. H. (1982). Summary and derivation of equating methods used at ETs. In P.W. Holland \& 
D. B. Rubin (Eds.), Test equating (pp. 51-69). New York: Academic Press.

Angoff, W. H. (1971). Scales, norms, and equivalent scores. In R. L. Thomdike (Ed.), Educational measurement (pp. 508-600). Washington DC: American Council on Education. (Reprinted by Educational Testing Service, Princeton $\mathbb{N} J, 1984$.)

Angoff, W. H., \& Cowell, W. R. (1985). An examination of the assumption that the equating of parallel forms is population independent (RR-85-22). Princeton $N J$ : Educational Testing Service.

Brandenburg, D. C., \& Forsyth, R. A. (1974). Approximating standardized achievement test norms with a theoretical model. Educational and Psychological Measurement, 34, 3-9.

Braun, H. I., \& Holland, P. W. (1982). Observed score test equating: A mathematical analysis of some ETS equating procedures. In P. W. Holland \& D. B. Rubin (Eds.), Test equating (pp. 9-49). New York: Academic Press.

Cook, L. L. (1984). Equating refurbished achievement tesis (unpublished statistical report). Princeton NI: Educational Testing Service.

Cook, L. L., \& Eignor, D. R. (1981, April). Score equating and item response theory: Some practical considerations. Paper presented at the annual meeting of the American Educational Research Association and the National Conference on Measurement in Education, Los Angeles.

Cook, L. L., Eignor, D. R., \& Taft, H. (1985). A comparative siudy of curriculum effects on the stability of $I R T$ and conventional item parameter estimates $(\mathbb{R} R$ 85-38). Princeton ND: Educational Testing Service.

Cureton, E. E., \& Tukey, J. W. (1951). Smoothing frequency distributions, equating tests, and preparing norms. American Psychologist, 6, 404. (Abstract.)

Eignor, D. R. (1985). An investigation of the feasibility and practical outcomes of pre-equating the SAT verbal and mathematical sections (RR-85-10). Princeton NI: Educational Testing Service.

Fairbank, B.A. (1985). Equipercertile test equating: The effects of presmoothing and postsmoothing on the magnitude of sample-dependent errors (AFHRL-TR84-64). Brooks Air Force Base TX: U.S. Air Force Human Resources Laboratory.

Henrysson, S. (1971). Gathering, analyzing, and using data on test items. In R. L. Thorndike (Ed.), Educational measurement (2nd ed., pp. 130-139). Washington DC: American Council on Education.

Holland, P. W., \& Rubin, D. B. (1982). Test equating. New York: Academic Press.

Keats, J. A., \& Lord, F. M. (1962). A theoretical distribution for mental test scores. Psychometrika, 27, $59-72$.

Kingston, N. M., \& Dorans, N. $\mathbb{H} .(1984)$. Item location effects and their implications for IRT equating and adaptive testing. Applied Psychological Measurement, 8, 147-154.

Kingston, N., Leary, L., \& Wightman, L. (1985). An exploratory study of the applicability of item response theory methods to the Graduate Management Admissiorss Test (RR-85-34). Princeton NV: Educational Testing Service.

Klein, L. W., \& Jarjoura, D. (1985). The importance of content representation for common-item equating with nonrandom groups. Journal of Educational Measurement, 22, 197-206.

Klein, L. W., \& Kolen, M. J. (1985, April). Effect of number of common items in common-item equating with nonrandom groups. Paper presented at the annual meeting of American Educational Research Association, Chicago.

Kolen, M. J. (1984). Effectiveness of analytic smoothing in equipercentile equating. Journal of Educational Siatistics, 9, 25-44.

Lord, F. M. (1950). Notes on comparable scales for test scores $(\mathbb{R B}-50-48)$. Princeton $\mathbb{N J}$ : Educational Testing Service.

Lord, F. M. (1977). Practical applications of item characteristic curve theory. Journal of Educational Measurement, 14, 117-138.

Lord, F. M. (1980). Applications of item response theory to practical testing problems. Hillsdale NJ: Erlbaum.

Lord, F. M., \& Wingersky, M. S. (1984). Comparison of IRT true-score and equipercentile observed-score " "equatings." Applied Psychological Measurement, 8 , $453-461$.

McKinley, R. L., \& Reckase, M. D. (1981). A comparison of procedures for constructing large item pools (Research Report 81-3). Columbia MO: University of Missouri, Department of Educational Psychology.

Petersen, N. S., Cook, L. L., \& Stocking, M. L. (1983). IRT versus conventional equating methods: A comparative study of scale stability. Joumal of Educational Statistics, 8, 137-156.

Raju, N. S., Edwards, J. E., \& Osberg, D. W. (1983, April). The effect of anchor test size in vertical equating with the Rasch and three-parameter models. Paper presented at the annual meeting of the National Council on Measurement in Education, Montreal.

Reinsch, C. H. (1967). Smoothing by spline functions. Numerische Mathematik, 10, 177-183.

Stocking, M. L., \& Lord, F. M. (1983). Developing a common metric in item response theory. Applied Psychological Measurement, 7, 201-210.

Tapia, R. A., \& Thompson, I. R. (1978). Non-parametric probability density estimation. Baltimore $\mathrm{MD}$ : Johns Hopkins University Press.

Tukey, J. W. (1977). Exploratory data analysis. Read- 
ing MA: Addison-Wesley.

Vale, C. D., Maurelli, V. A., Gialluca, K. A., Weiss, D. J., \& Ree, M. J. (1981). Methods for linking item parameters (AFHRL-TR-81-10). Brooks Air Force Base TX: U.S. Air Force Human Resources Laboratory.

Wingersky, M. S. (1983). LoGIST: A program for computing maximum likelihood procedures for logistic test models. In R. K. Hambleton (Ed.), Applications of itew response theory. Vancouver: Educational Research Institute of British Columbia.

Wingersky, M. S., Cook, L. L., \& Eignor, D. R. (1986, April). Specifying the characteristics of linking items used for item response theory item calibration. Paper presented at the annual meeting of the American Educational Research Association, San Francisco.

Wingersky, M. S., \& Lord, F. M. (1984). An investigation of methods for reducing sampling error in cer- tain IRT procedures. Applied Psychological Measirement, 8, 347-364.

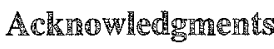

The authors' mames are in alphabetical order. The authors gratefully acknowledge the technical assistance of Daniel R. Eignor and Marilyn S. Wingersky in the preparation of some sections of this paper.

\section{Arathor ${ }^{3}$ s Address}

Send requests for reprints or further information to Linda L. Cook, Mail Stop 31-E, Educational Testing Service, Rosedale Road, Princeton NI 08541, U.S.A. 